\title{
LATERAL TESTS ON A TWO-STORY CLT HOUSE
}

\author{
Jorge M. Branco, Filipe T. Matos, Paulo B. Lourenço \\ University of Minho, Guimarães, Portugal
}

\author{
Thomas Demschner
}

Stora Enso, Ybbs, Austria

\section{Patrício Rocha}

Polytechnic Institute of Viana do Castelo, Viana do Castelo, Portugal

Contacting author: jbranco@civil.uminho.pt

\begin{abstract}
A two storey full-scale model of a CLT house, of $4.5 \mathrm{~m} \times 9.1 \mathrm{~m}$ in-plane, with a height of $5.04 \mathrm{~m}$, was tested under quasi-static monotonic (pushover). The main objectives were to investigate the 3-D system performance of a CLT structure subjected to lateral loads in terms of lateral strength and deformability capacity, global behaviour of the structure, frequency response of the structure, performance of connectors (mainly hold-downs and angle-brackets) and connections between CLT panels. Lateral loads have been applied on the storeys inducing torsion to the building. Loading procedure, number and disposition of connectors varied between tests.

With this campaign it is intended to obtain results on: i) load-deformation response of a 3-D CLT structure subjected to lateral loads; ii) global response of the structure, focusing on the performance of CLT slabs subjected to in-plane loads, performance of parallel and perpendicular walls, and response of the structure near openings; iii) failure mechanisms and on the performance of connections between CLT panels and connectors. The outcomes of the full-scale CLT house tests will be used for further analytical and numerical analyses to help implement the new generation of Eurocode 8.
\end{abstract}

Keywords: Cross Laminated Timber; Seismic design; Full-scale tests; Eurocode 8

\section{Introduction}

In the last few years, full-scale tests on CLT buildings have been used to assess the performance of these new structures. The purpose has been to analyze the global performance of the structure after the tests performed on individual members, slabs and specially walls. Nevertheless, it was also of particular interest to evaluate the response of the connections materialized by metal devices like angle brackets and hold-downs based on cyclic tests. Among the tests performed in a shaking table, it is important to point out the SOFIE project, in which a three stories building with $7 \mathrm{mx}$ $7 \mathrm{~m}$ in plan and $10 \mathrm{~m}$ of total height including the 
roof, was tested for three different configurations (variation of openings). The building was subjected to a series of 26 earthquakes, including the great Hanshin-Awaji earthquake (in Kobe, in 1995), at the NIED Laboratory, in Tsukuba, in July 2006. In terms of results, the building resisted to 15 destructive earthquakes without any serious damage and no significant torsion was recorded [1]. Another high building with seven stories, was tested, in 2007, in the shaking table of the E-Defense laboratory in Miki, Japan. The building with $13.5 \mathrm{~m} \times 7.5 \mathrm{~m}$ and a total height of $23.5 \mathrm{~m}$, was submitted to the JMA Kobe earthquake, the Italian earthquake of Nocera Umbra and Kashiwazaki. At the level of the panels' thickness, the walls of the building had $142 \mathrm{~mm}$ on the $1^{\text {st }}$ and $2^{\text {nd }}$ storey, $125 \mathrm{~mm}$ on the $3^{\text {rd }}$ and $4^{\text {th }}$ storey and $85 \mathrm{~mm}$ in the others, including the roof. All the floors were $142 \mathrm{~mm}$ thick. The tests performed provided the researchers excellent results, as the building behaved very well on largescale earthquakes, with very low structural damage. However, relatively high floor accelerations (maximum acceleration of $3.8 \mathrm{~g}$ ) were recorded [2]. On the other hand, two singlestories CLT models were tested in 2006, at the Dynamic Testing Laboratory of the Institute of Earthquake Engineering and Engineering Seismology from the University of Ljubljana, Slovenia, using different earthquake records with PGA (Peak ground acceleration) of $0,6 \mathrm{~g}$. As expected, no major damage was found [3]. More recently, another CLT full-scale building was tested on the shaking table of the National Laboratory for Civil Engineering (LNEC), Portugal. In the scope of a SERIES project aimed to evaluate multi-stories timber buildings, researchers from Graz University and LNEC tested a 3-storey CLT building with $5.17 \mathrm{~m}$ $x 6.79 \mathrm{~m}$ in plan and $7.74 \mathrm{~m}$ of total height, including the roof $(5,36 \mathrm{~m}$ at the second floor). In terms of CLT components, the walls were composed of $100 \mathrm{~mm}$ (3-layers) panels, the floors with $150 \mathrm{~mm}$ (5-layers) and the roof with $99 \mathrm{~mm}$ (3-layers). The steel connections used were angle brackets (AE116 Simpson Strong Tie) and hold-downs (HTT22 Simpson Strong Tie) with the corresponding nails and screws. The building was subjected to 32 seismic tests, in which the maximum ground acceleration was $0.5 \mathrm{~g}$ At the conclusion of these tests, the building presented minor damages (located in some connections and walls) with a decrease of the fundamental frequency of $3.98 \mathrm{~Hz}$ to $3.75 \mathrm{~Hz}$ [4]. A different approach, based on quasistatic tests, was used to test a CLT building with $6.0 \mathrm{~m} \times 4.8 \mathrm{~m}$ in plan with a height of $4.8 \mathrm{~m}$, by Popovski and Gavric (2015). Most of the connections used were angle brackets (BMF $116 \mathrm{x}$ $48 \times 3 \times 116)$ and hold-downs (HTT4) but their number and location was a variable in each test performed. The specimen was tested under monotonic and cyclic lateral loading, in a total of five tests. The main failure mechanisms were the nails in the brackets at the bottom of the 1st story, in all tests, as a consequence of sliding and rocking (uplift) deformations of the walls. At the level of the fundamental frequency, the building before the tests, presented a $13.5 \mathrm{~Hz}(\mathrm{E}-\mathrm{W})$ and $11 \mathrm{~Hz}(\mathrm{~N}-$ S). After all the tests, the values decreased to 10.13 $\mathrm{Hz}$ and $7.63 \mathrm{~Hz}$, respectively $[5,6]$. In this context, an experimental program based on quasi-static tests was planned at the University of Minho, Portugal, using a 2-storey CLT building, with the main research aim being to analyze the 3-D system performance when subjected to lateral loads. The main variables for the experimental program were the analysis of lateral resistance and deformability capacity, global behavior of the structure, frequency response of the structure and the performance of connectors (mainly AE116 and HTT22 from Simpson Strong-tie). The building was designed with the aim to obtain a non-symmetric structure, with a clear distinction between the longitudinal (stiffer) axis and the transverse one and assuming that the center of mass had to be different from the center of stiffness. Moreover, to avoid a possible overlap of effects, it was assumed that when the metal connectors would be placed only in the CLT walls, working as shear walls in each loading direction. In the following sections, the tests performed, the results obtained, including the preparation works are presented and discussed.

\section{Experimental campaign}

The CLT building under analysis was subjected a two quasi-static monotonic tests, one for each direction (transverse and longitudinal axis), in which the angle brackets and hold-downs were introduced only in the shear walls in the direction of the lateral forces applied. The house has a plan of $4.5 \mathrm{~m} \times 9.1 \mathrm{~m}$, with two floors, with a total height 
of $5.04 \mathrm{~m}$. Several partition walls and several openings were created (staircase on the 1st floor and on the external walls), with the purpose of creating an asymmetric structure prone to torsion. With regard to the CLT panels, they were produced by Stora Enso Wood Products Ltd., made of spruce, with a density of $5 \mathrm{kN} / \mathrm{m}^{3}$. In terms of thickness, the wall of CLT panels had $100 \mathrm{~mm}$ (5-layers of $20 \mathrm{~mm}$ ) and the floors were made of $120 \mathrm{~mm}$ CLT panels (3layers with $40 \mathrm{~mm}$ ). The building plans with the description of the shear walls and facades, can be seen in Figure 1.

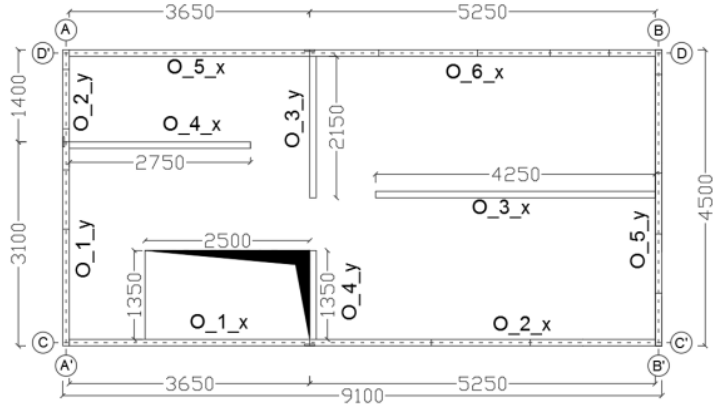

(a)

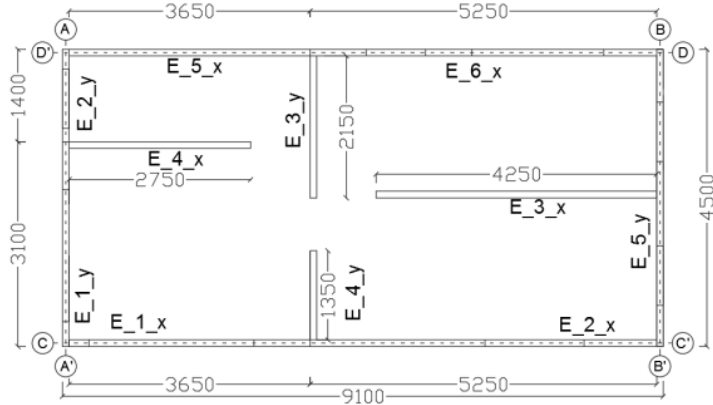

(b)

Figure 1. Building plans (dimensions in $\mathrm{mm}$ ). (a) $1^{\text {st }}$ story; (b) $2^{\text {nd }}$ story

Due to transport reasons, the exterior walls (O_1_x, O_2_x, O_5_x, O_6_x, O_1_y, O_2_y, E_1_x, E_2_x, E_5_x, E_6_x, E_1_y, and E_2_y) were defined as segmented walls. As to the connections between the CLT panels, the surface spline method [7] has been adopted (see Figure 2) to joint two adjacent panels, with the introduction of a wooden board fixed with screws to ensure the continuity of the wall. In the same way, the floors were divided into five segments using the same connection method of the walls.

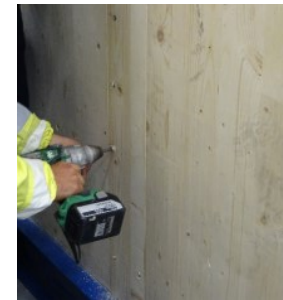

(a)

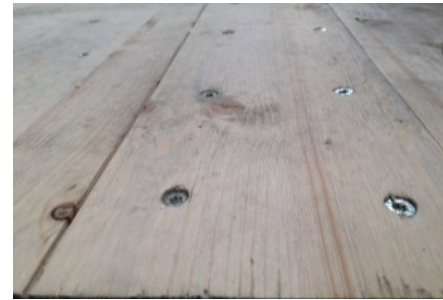

(b)
Figure 2. Typical typology used of connection wall-to-wall (a) and floor-to-floor (b) segmented

Regarding the openings of the walls, several windows and doors were created, except in the internal walls and external walls $0 \_1 \_x, 0 \_5$ x $x$ and E_5_x as depicted in Figure 3 .
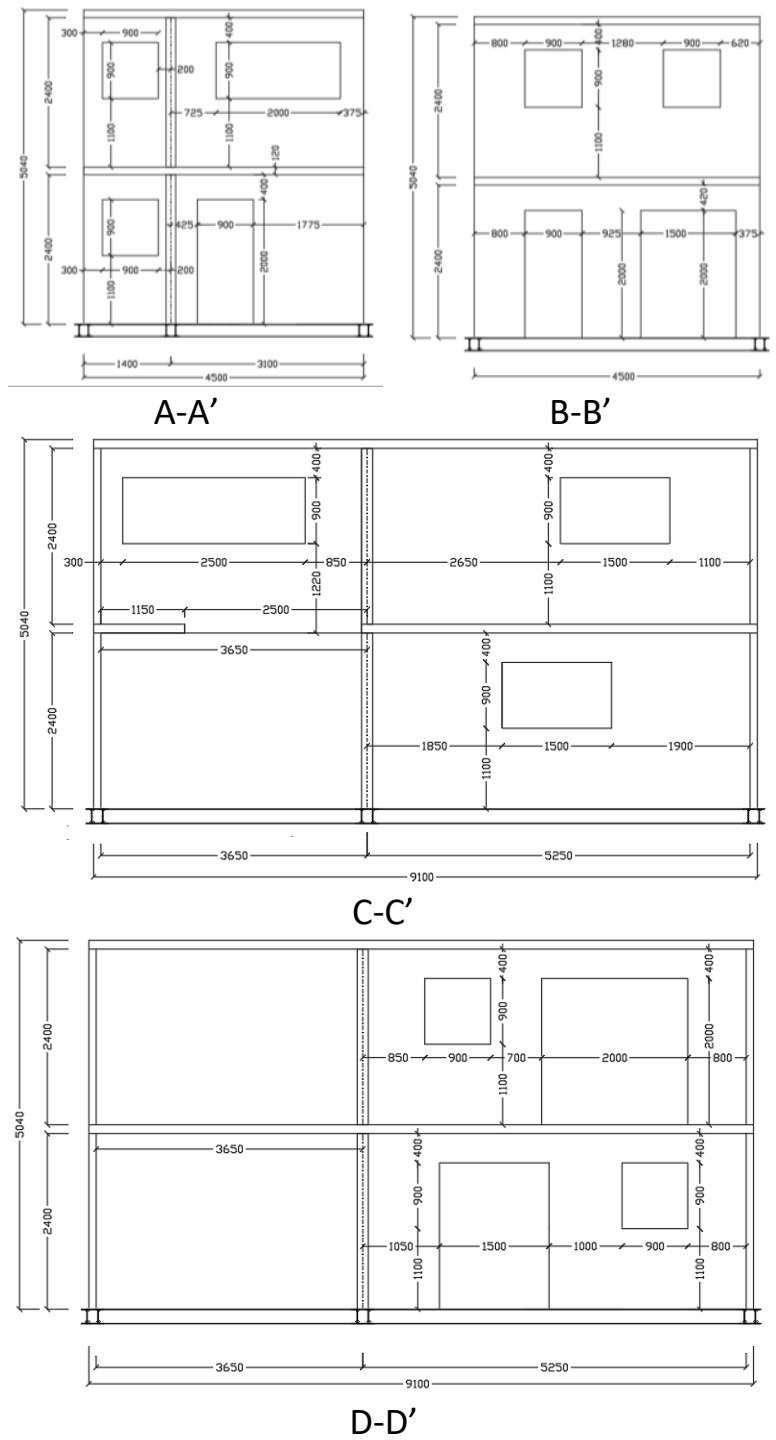

Figure 3. Building facades with measures of the openings and height of walls (dimensions in $\mathrm{mm}$ ) 
The remaining permanent loads and percentage of the live-load with application of the coefficient for variable action (combinations of the seismic action of Eurocode 8), were placed over the building as additional masses, by distributing drums of water over the floors as shown in Figure 4. A total of 2 $\mathrm{kN} / \mathrm{m}^{2}$ and a $1.7 \mathrm{kN} / \mathrm{m}^{2}$ were applied for the first and second floor of the building, respectively.

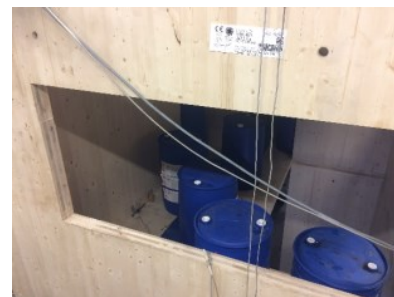

(a)

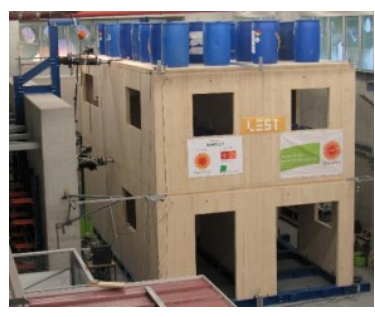

(b)
Figure 4. Additional masses used in the tests. (a) $1^{\text {st }}$ floor; (b) $2^{\text {nd }}$ floor

Connections play an important role in the performance of CLT buildings and this case is no exception. The connections between the different CLT panels are crucial do ensure an adequate overall behavior of the system, keeping the different structural elements connected, while the local behavior of joints is fundamental to assure the deformability, ductility and energy dissipation capacities needed. The connections used represent the common techniques used in practice, based on the use of angle brackets as shear connectors, holddowns taking the uplift forces (tension) and adding screws to increase the stiffness of the connections. The metal connectors used, angle-brackets and hold-downs were supplied by Simpson Strong-tie while the screws were from Rothoblaas. In addition, to ensure a perfect distribution of the forces introduced by the hydraulic jacks at the floors level, steel plates were placed in both floors, in both loading directions, longitudinal and transverse, screwed to the CLT panels. Table 1 summarizes the different types of connections used and their locations.

Table 1. Connections and locations used in the CLT building

\begin{tabular}{l} 
Quantity - Location \\
\hline AE116 + 14 $\times$ CNA Annular ring nails $(\varnothing 4 \times 60 \mathrm{~mm})+$ \\
2 Threaded road $\emptyset 12-$ AE116 Ground floor \\
\hline AE116 $+(14+7) \times$ CNA Annular ring nails \\
$(\varnothing 4 \times 60 \mathrm{~mm})-$ AE116 $1^{\text {st }}$ floor
\end{tabular}

HTT22 + Threaded road $\emptyset 16+15 \times$ CNA Annular ring nails $(\varnothing 4 \times 60 \mathrm{~mm})-$ HTT22 Ground floor

HTT22 + Threaded road $\emptyset 16+15 \times$ CNA Annular ring nails $(\varnothing 4 \times 60 \mathrm{~mm})-\mathrm{HTT} 22 \mathbf{1}^{\text {st }}$ floor

$3 \times$ Perforated plate $120 \times 240 \mathrm{~mm}$ thickness $2 \mathrm{~mm}$

- Wall-to-wall (staircase)

HBS+ EVO $\varnothing 8 \times 60 \mathrm{~mm}+$ Threaded road $\emptyset 12$ - Steel plate on the floors

$2 \times$ (HBS $\emptyset 6 \times 80 \mathrm{~mm})$ spaced to $150 \mathrm{~mm}$ - Wall-towall (wooden board)

$2 \times$ (HBS $\emptyset 6 \times 100 \mathrm{~mm})$ spaced to $150 \mathrm{~mm}$ - Floorto-floor (wooden board)

HBS $\emptyset 8 \times 220 \mathrm{~mm}$ spaced to $150 \mathrm{~mm}$ - Wall-to-wall

VGZ Ø9×240mm spaced to $150 \mathrm{~mm}$ - Floor-to-wall

In the definition and design of the connections used in the CLT building, the methodology proposed by Eurocode 8 [8] was adopted. For that, the Rayleigh method was used to predict the natural frequencies of the building under study. By applying this $2 \mathrm{D}$ analysis method, frequencies of $3.6 \mathrm{~Hz}$ and $2.6 \mathrm{~Hz}$ were obtained, for the longitudinal and transverse directions, respectively. The seismic base shear force used for the design was $138 \mathrm{kN}$ corresponding to frequencies of $3.6 \mathrm{~Hz}$ and $2.6 \mathrm{~Hz}$ for the longitudinal and transverse direction, respectively [8].

\subsection{Monotonic tests}

The quasi-static monotonic tests carried out consisted on the application of a displacement under a constant rate, on each floor, respecting the ISO/FDIS 21581:2010. Two hydraulic jacks were used, one in each floor, to apply the displacements under a constant rate of $0.08 \mathrm{~mm} / \mathrm{s}$ and $0.04 \mathrm{~mm} / \mathrm{s}$ on the second and first floor, respectively. Due to technical limitations, namely the load capacity of the hydraulic jack installed in the second floor, the criterion adopted to stop the tests was a load value of $300 \mathrm{kN}$ in that hydraulic jack. Two tests were performed: Test 1 in the longitudinal direction and Test 2 in the transverse direction. As already mentioned, the number and location of the connections varied with the test to be performed. The idea was to apply connectors only in the shear walls (walls in the direction of the load application) for each test. Table 2 shows the angle brackets 
(AE116) and hold-downs (HTT22) used in each shear wall in the two tests performed.

Table 2. Number of metal connectors (AE116 and HTT22) used in each test

\begin{tabular}{|c|c|c|c|}
\hline Test & Wall & AE116 & HTT22 \\
\hline \multirow{12}{*}{ Test 1} & 0_1_x & 3 & 2 \\
\hline & $0 \_2 \_x$ & 3 & 2 \\
\hline & 0_3_x & 2 & 2 \\
\hline & O_4_x & 2 & 2 \\
\hline & 0_5_x & 3 & 2 \\
\hline & $06 x$ & 3 & 4 \\
\hline & E_1_x & 1 & 1 \\
\hline & $E-2 \_x$ & 4 & 2 \\
\hline & E_3_x & 2 & 2 \\
\hline & E_4_x & 2 & 2 \\
\hline & E_5_x & 2 & 2 \\
\hline & E_6_x & 3 & 4 \\
\hline \multirow{10}{*}{ Test 2} & O_1_y & 2 & 4 \\
\hline & O_2_y & 2 & 2 \\
\hline & O_3_y & 2 & 2 \\
\hline & $044 y$ & 2 & 2 \\
\hline & O_5_y & 4 & 6 \\
\hline & E_1_y & 3 & 2 \\
\hline & E_2_y & 1 & 2 \\
\hline & E_3_y & 2 & 2 \\
\hline & E_4_y & 2 & 2 \\
\hline & E_5_y & 4 & 2 \\
\hline
\end{tabular}

\subsection{Test set up and instrumentation}

The test setup was developed based on the need to have two lateral applications of load, one in each floor, in both directions of the CLT building. Here, only the monotonic tests performed are presented but the setup also allows lateral cyclic loading. The main concerns of the test setup developed were: i) to have a rigid steel base to ensure an adequate fixation of the building to the reaction floor of the lab including the fixation of the CLT panels of the first floor to the base through angle-brackets (AE116) and hold-downs (HTT22), as discussed above (Figure 5a); ii) to place and fix the two hydraulic jacks responsible for applying the lateral loads in both axis of the building (Figure $5 b$ and Figure 5c). The hydraulic jacks included one hinges in each extremity, to avoid parasite deformations and stresses, were placed in the middle of the façades; and, iii) to ensure that the load applied by the hydraulic jacks on the CLT of the floors is distributed (Figure 5d).

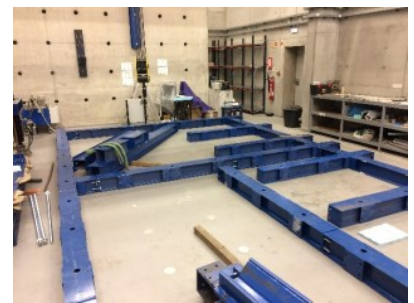

(a)

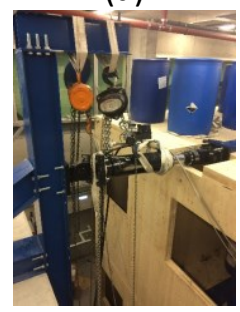

(c)

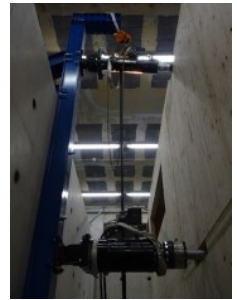

(b)

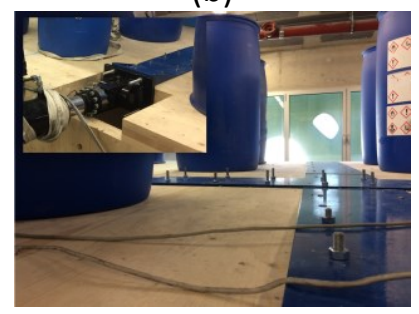

(d)
Figure 5. Steel base structure (a), support structure of the hydraulic jacks on transverse (b) and longitudinal direction (c) and a steel plates placed on the floors (d)

The instrumentation system included the use of 12 accelerometers (see Figure 6), placed in defined positions, to determine the natural frequencies of the CLT building. This information is of crucial importance to analyze the behavior of the structure, for the design of the connections and to detect if damage was introduced in the building by the tests performed. However, due to time limits, in this paper only the identification of the natural frequencies with and without additional masses, before the tests, will be presented.

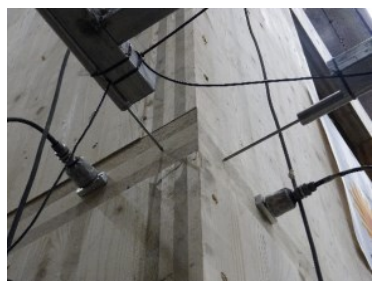

(a)

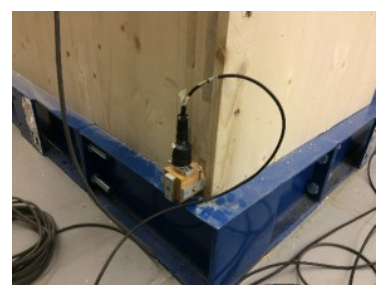

(b)
Figure 6. Accelerometers installed on the building. (a) Method used in the $1^{\text {st }}$ and $2^{\text {nd }}$ floor; (b) Method used on the ground floor

For the measurement of the displacement during each test, 24 LVDTs (Linear Variable Differential Transformer) were placed in defined positions, ensuring that not only the global deformation of the building in each direction was measured but also that the in-plane deformation, rotation of the 
floors, uplift of the walls panels and sliding were accurately registered (see Figure 7).

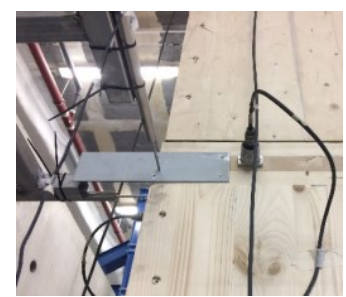

(a)

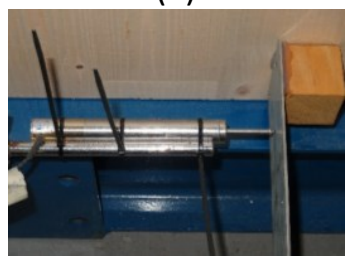

(c)

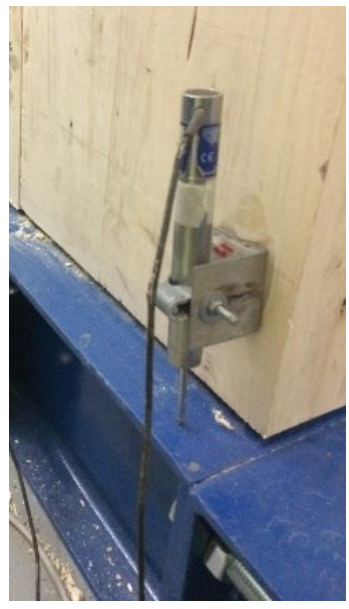

(b)
Figure 7. Examples of LVDTs used to register

(a) in- plane-deformation of the floors; (b) uplift of the wall panels; and (c) sliding

\section{Results and discussion}

In this section, the main results collected during the two monotonic tests performed are briefly presented.

Figure 98 and 9 show the experimental curves for the base shear force-horizontal displacement on the top of the building. It is important to note that tests were stopped when the criterion of the limitation for the load applied by the hydraulic jack of the second floor $(300 \mathrm{kN})$ was reached. As expected, those experimental curves demonstrate that the CLT building is stiffer in the longitudinal direction when compared with the transverse one, with a significant increase of the load-carrying capacity of the structure in that direction. It is also important to note that no failure was observed with Test 1 , in longitudinal direction and, therefore, the maximum base shear force registered is limited by the technical limitations already reported (the hydraulic jack of the second floor has a maximum load capacity of $300 \mathrm{kN}$ ). The same did not happen in Test 2, some damage being visible on the wall panels when the building was loaded in the transverse direction. But, more details will be presented below.
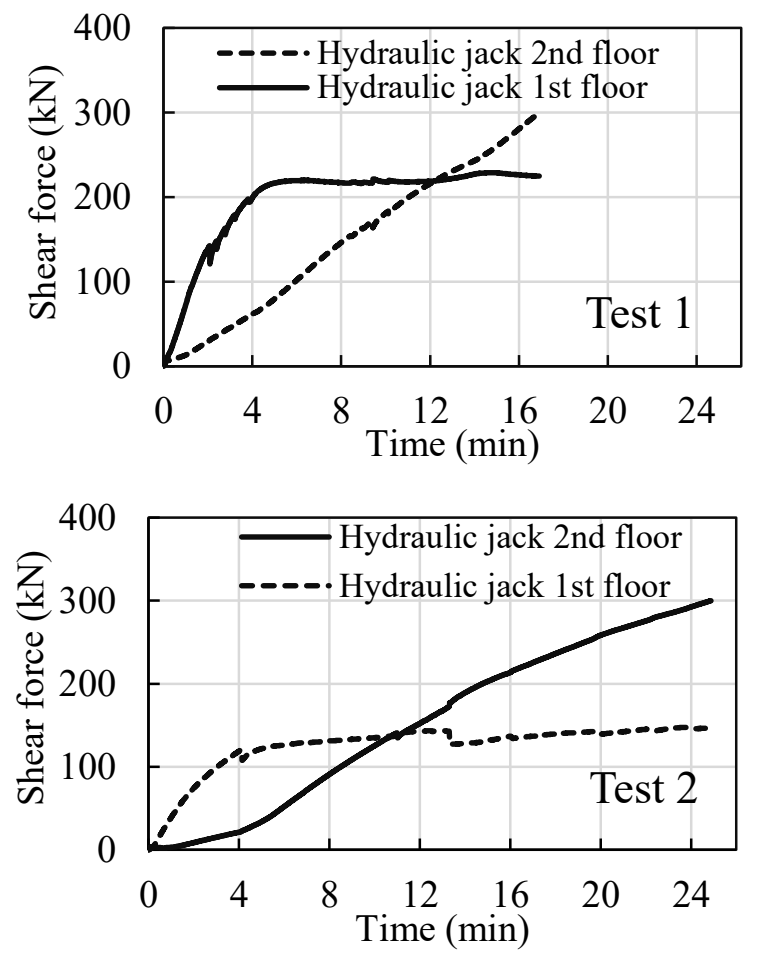

Figure 8. Shear force-time on hydraulic jacks on the floors during Test 1 (longitudinal direction) and Test 2 (transverse direction)

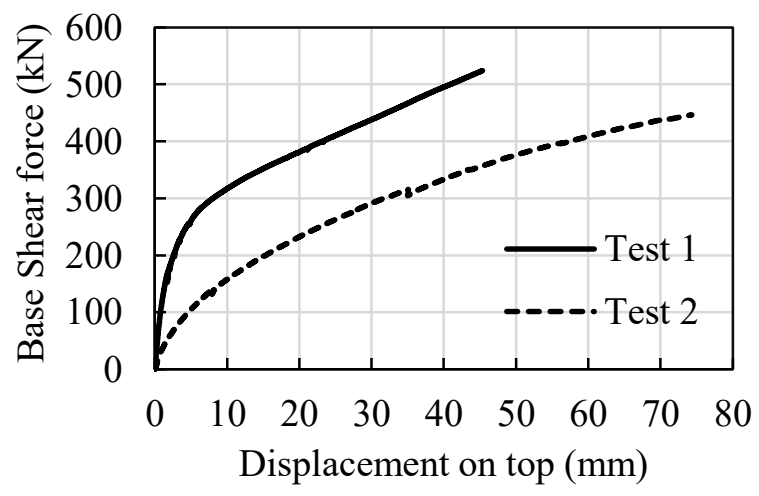

Figure 9. Base shear force-total displacement on top of the CLT building registered during Test 1 (longitudinal direction) and Test 2 (transverse direction)

Table 3 summarizes the most relevant data taken by the instrumentation system, namely the horizontal displacement at the floor levels and the uplift measured between the walls panels and the base and wall panels and the first floor. The base shear force values are also listed to help to understand the difference of behavior observed during both tests or, in other words, in both direction of the application of the lateral loads. 
Table 3. Main results for the base shear and displacements measured during the tests

\begin{tabular}{lcc}
\hline Test & Test 1 & Test 2 \\
\hline $1^{\text {st }}$ story shear force $(\mathrm{kN})$ & 228.41 & 147.67 \\
\hline $2^{\text {nd }}$ story shear force $(\mathrm{kN})$ & 300.00 & 300.00 \\
\hline Total Base shear force $(\mathrm{kN})$ & 528.41 & 447.67 \\
\hline $\begin{array}{l}1^{\text {st }} \text { story horizontal } \\
\text { displacement }(\mathrm{mm})\end{array}$ & $\begin{array}{c}34.54 \\
(0.69 \% \mathrm{H})\end{array}$ & $\begin{array}{c}47.36 \\
(0.84 \% \mathrm{H})\end{array}$ \\
\hline $\begin{array}{l}2^{\text {nd }} \text { story horizontal } \\
\text { displacement }(\mathrm{mm})\end{array}$ & $\begin{array}{c}45.87 \\
(0.91 \% \mathrm{H})\end{array}$ & $\begin{array}{c}74.34 \\
(1.48 \% \mathrm{H})\end{array}$ \\
\hline $\begin{array}{l}1^{\text {st }} \text { floor shear walls - uplift } \\
(\mathrm{mm})\end{array}$ & 7.87 & 16.57 \\
\hline $\begin{array}{l}2^{\text {nd }} \text { floor shear wall - uplift } \\
(\mathrm{mm})\end{array}$ & 0.07 & 2.65 \\
\hline
\end{tabular}

$\mathrm{H}-$ total height of the building

Based on the global values measured during both tests for horizontal displacements, it is possible to conclude that the deformation values are low even for very high values of lateral forces applied. Because the maximum load was not reached due to the technical limitation of the maximum capacity of the hydraulic jack of the second floor $(300 \mathrm{kN})$, applying the criteria defined by ISO/FDIS 21581 (2010), of $6.66 \%$ of the total height of the building, it is clear that the values obtained are quite far from that limit. Again, the difference between the stiffness of the CLT building in both direction is demonstrated. In relation to the uplift, both tests had uplift on the shear walls of the $1^{\text {st }}$ floor, in which the highest value was reached on test 2 . As one might expect, and by the low values of uplift, the values of shear walls of the $2^{\text {nd }}$ floor are practically irrelevant. Dynamic identification was applied to determine the natural frequencies of the CLT building, with and without additional masses, as described in Table 4.

Table 4. Natural frequencies obtained before and after the addition of the additional masses.

\begin{tabular}{ccc}
\multirow{2}{*}{ Schedule } & \multicolumn{2}{c}{ Frequency $(\mathrm{Hz})$} \\
\cline { 2 - 3 } & Longitudinal & Transverse \\
\hline $\begin{array}{c}\text { Without additional } \\
\text { masses }\end{array}$ & 19.24 & 8.16 \\
$\begin{array}{c}\text { With additional } \\
\text { masses }\end{array}$ & 12.53 & 5.01 \\
\hline
\end{tabular}

In addition to the analysis of the main results obtained, in terms of natural frequencies and deformation of the CLT building, Figure 10 shows the most relevant damages observed in the structure during Test 1 (longitudinal direction).

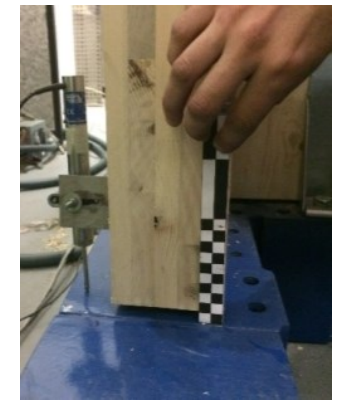

(a)

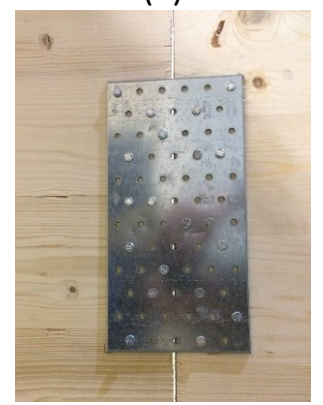

(c)

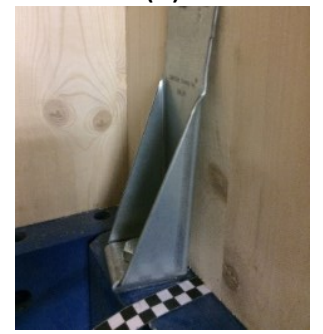

(e)

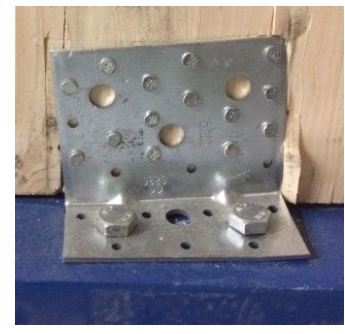

(g)

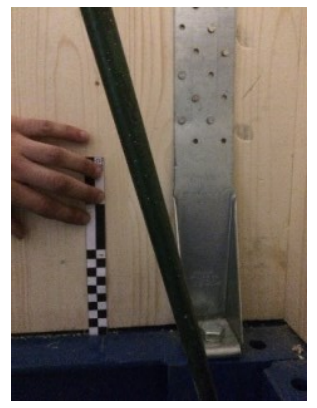

(b)

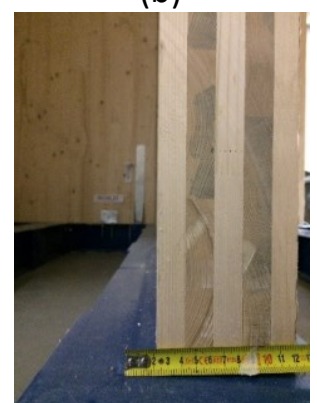

(d)

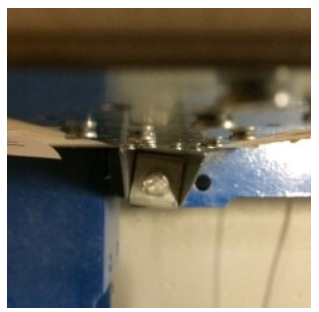

(f)

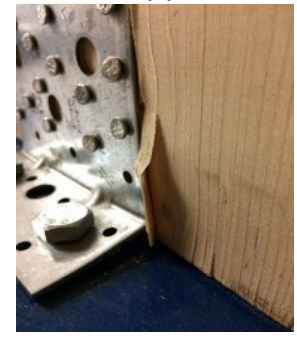

(h)

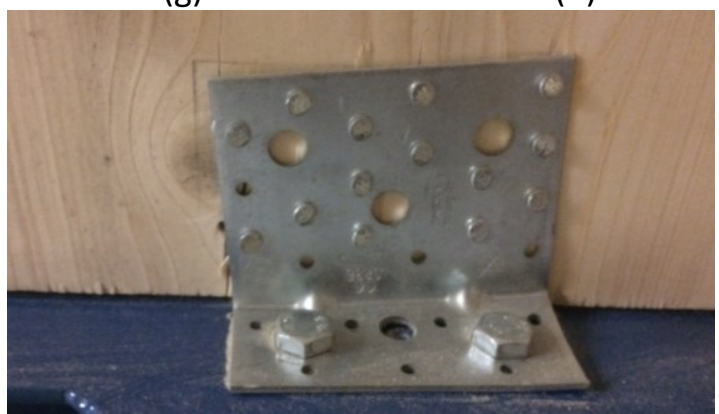

(i)

Figure 10. Main damages observed during Test 1. Rotation located on the walls $O_{-} 1_{-} y(a)$ and $E_{-} 1_{-} x$ 
(b); (c) uplift of intersection of the walls $0 \_1 \_x$ with $E_{-} 1_{-} x ;(d)$ translation of the transverse wall O_3_y; rotation of the HTT22 connections on the wall O_6_x near to internal wall O_3_y (e) and near to the door opening (f); sliding $((g)$ and $(h))$ and uplifting (i) of the wall $O_{-} 2$ _ $x$

The building suffered a global uplift of about 8 millimeters, concentrated at the base level (Figure 10a and Figure 10b) and practically insignificant between the walls of the second floor and the first floor, with exception of a small uplift visible in the staircase walls where there is no CLT floor (see Figure 10c).

In terms of in-plan rotation of the building, as the center of mass is different from the center of stiffness and as non- metal connectors (anglebrackets and hold-downs) were placed in transverse walls in relation to the load application, the building suffered a significant lateral translation of those interior walls (see Figure 10d). Most of the damage observed was located in the metal connectors. As it is possible to observe in Figure 10f, Figure 10g, Figure $10 \mathrm{~h}$ and Figure 10i, some connectors were damaged as consequence of sliding or rotation (uplift). Moreover, in some cases, AE116 connectors underwent a small uplift, in which the screws that connect the steel structure of the base did not presented any changes (see Figure 10h). On the other hand, and as expected, the damages observed during Test 2 , were more burdensome, due to the fact that this loading direction, transverse of the building, is the one with less stiffness (see Figure 11). More severe damages were observed than in Test 1 , and due to the higher level of damage imposed, in consequence of the higher deformation force, two distinct types of damages were observed. Now, the uplift of the CLT panels of the second floor in relation to the CLT panels of the first floor was visible (see Figure 11a). Then, the lintels over the openings of the wall 0 _5_y (see Figure $11 \mathrm{~b}$ and Figure 11c) cracked by tension perpendicular to the grain. During Test 2 it was possible to observe the lateral translation of the internal walls (see Figure 10d) placed perpendicular to the loading direction (longitudinal axis of the building), the uplift of HTT22 connectors (see Figure 11e and Figure 11f) and some angle brackets presenting sliding (Figure $11 \mathrm{~g})$, rotation (Figure 10h) and uplift (Figure 11i).

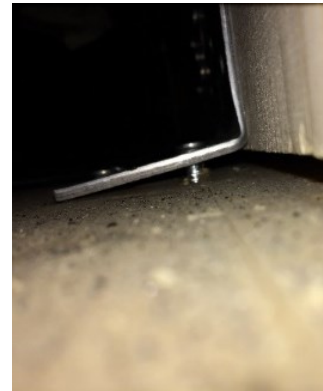

(a)

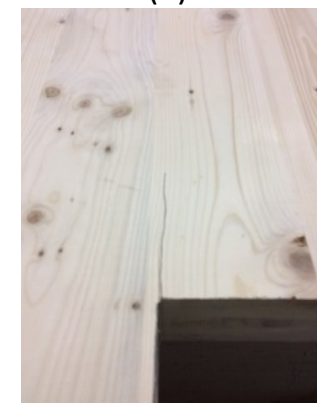

(c)

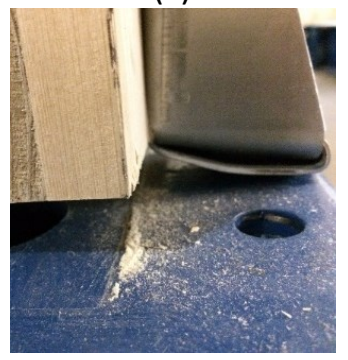

(e)

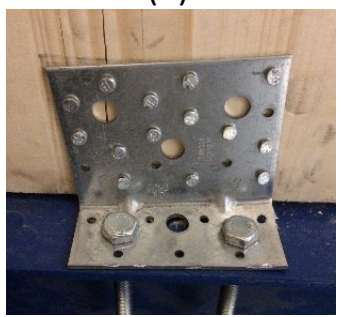

(g)

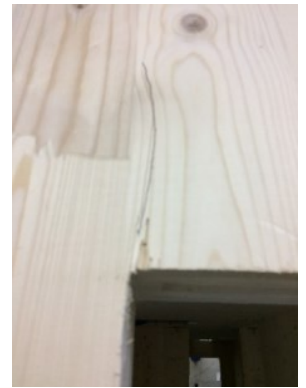

(b)

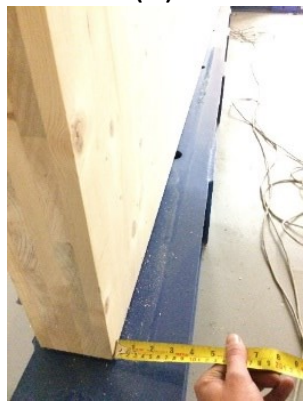

(d)

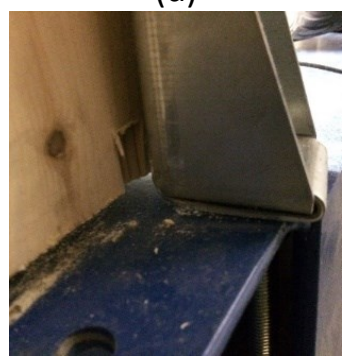

(f)

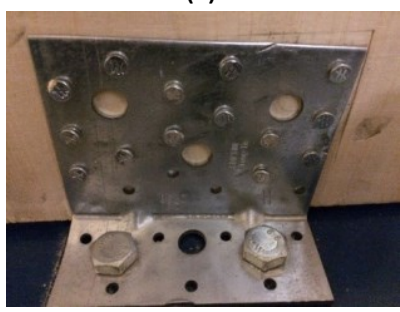

(h)

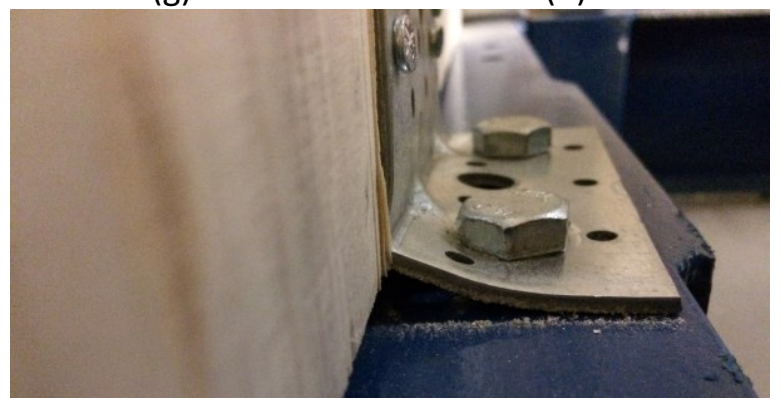

(i)

Figure 11. Main damages of the Test 2. (a) uplift of the AE116 connector nails on the wall E_5_y; cracks on top right corner of the openings $1500 \times 2000$ (b) and $900 \times 2000$ (c) on the wall O_5_y; (d) translation of the longitudinal wall 
O_3_x; uplift (e) and rotation (f) of the connections near to the opening $900 \times 2000$ and the internal wall O_3_x on the wall O_5_y; sliding $(g)$, rotation

(h) and uplift (i) of the connection AE116 on the wall O_3_y

\section{Conclusions}

After the tests were performed, and even with the analysis of the results having just started, it is possible to conclude that CLT buildings have a good performance under lateral loading as the ones caused by earthquakes. A non-symmetric structure was defined, large openings were considered and the effect of the position of the metal connectors was investigated. During the tests presented, the distinct performance in each loading direction was observed. In the longitudinal case, since the structure is stiffer, no significant damage was observed. This can be explained by the technical limitation of the hydraulic jack used in the second floor that presented a load capacity of $300 \mathrm{kN}$. In Test 1 , applying the lateral load in the longitudinal direction of the building, the damage observed was concentrated in the metal connectors (anglebrackets and hold-downs), with signs of sliding, rotation and uplift. On the other hand, in the transverse direction, with Test 2, with short shear walls, it was possible to observe more damage. The rotation of the overall structure was visible and the lintels over the larger openings cracked by tension perpendicular to the grain. The damage evolution was in agreement with what was the expected in view of past researches. The fundamental frequencies of the CLT building have been identified with and without masses. Further analysis is needed, but it seems obvious that the prediction based on the actual philosophy of Eurocode 8 needs to be improved.

\section{Acknowledgments}

A very special thanks to the contribution of Simpson Strong Tie that supplied all metal connectors used and to the technicians of the Structures Laboratory of the Civil Engineering Department at University of Minho for the time and dedication given during this experimental program.

\section{References}

[1] Ceccotti, A. and M. Follesa, Seismic behavior of multi-story X-Lam buildings. Proc., COST E29 Int. Workshop on Earthquake Engineering on Timber Structures, Dept. of Civil Engineering, Faculty of Sciences and Technology, Univ. of Coimbra, Portugal., 2006.

[2] Ceccotti, A., et al., SOFIE project-3D shaking table test on a seven-storey fullscale cross-laminated building. Earthquake Engineering \& Structural Dynamics, 2013. 42(13): p. pp. 2003-21.

[3] Dujic, B., et al., Experimental Investigation of Massive Wooden Wall Panel Systems Subjected to Seismic Excitation. Proceedings of the First European Conference on Earthquake Engineering and Seismicity, Geneva, Switzerland, 2006.

[4] Costa, A.C. and P.X. Candeias, Seismic perfomance of multi-storey timber buildings - TUGraz building. Final Rep. of Timber Buildings Project, 2013.

[5] Popovski, M. and I. Gavric, Performance of a 2-Story CLT House Subjected to Lateral Loads. J. Struct. Eng., 2015. 142(4).

[6] Popovski, M., I. Gavric, and J. Schneider, Performance of two-storey CLT house seubjected to lateral loads. Proceedings of the 12th World Conference on Timber Engineering WCTE 2014, Quebec, Canada., 2014.

[7] FPInnovations, CLT Handbook: CrossLaminatedTimber, Canadian Edition. Edited by Erol Karacabeyli and Brad Douglas. Library and Archives Canada Cataloguing in Publication, Quebec City, Canada., 2013.

[8] EN 1998-1:2004, Eurocode 8: Design of structures for earthquake resistance - Part 1: General rules, seismic actions and rules for buildings. EN1998-1:2004 CEN, Brussels, Belgium, 2004. 